\title{
Morpho-physiological and Molecular Variability in Salt Tolerant and Susceptible Popular Cultivars and their Derivatives at Seedling Stage and Potential Parental Combinations in Breeding for Salt Tolerance in Rice
}

\author{
K. ChattopadhyAY*, D. NAth, R.L. Mohanta, B.C. Marndi, D.P. Singh and O.N. Singh \\ Central Rice Research Institute, Cuttack, Odisha, India \\ (Received 6 February 2014; Accepted 18 August 2014; \\ Communicated by H. Bürstmayr)
}

\begin{abstract}
Saltol, a major QTL for salt exclusion, was derived from 'Pokkali', a salt-tolerant rice cultivar. Apart from Pokkali, many genotypes with wide variation for salinity tolerance offer ample scope for identifying new genes or QTLs underlying various tolerance mechanisms. Such genes could be aggregated into high-yielding backgrounds to reinforce a breeding programme. To identify potential donors for salt tolerance and prospective parental combinations for developing high-yielding salt-tolerant cultivars, ten genotypes were subjected to salt stress and evaluated for morpho-physiological traits and marker-allele polymorphism in the Saltol-QTL region. Although the salt-susceptible high-yielding varieties clustered together in a 3-D plot, principal component analysis showed marked spatial isolation among the tolerant genotypes. Unlike Pokkali and its derivative FL496, Rahspunjar maintained a higher level of $\mathrm{K}^{+}$despite high $\mathrm{Na}^{+}$influx in shoots. The wider genetic distances observed at both phenotypic and genotypic levels suggest the possibility of getting transgressive segregants among the offspring of crosses between Rahspunjar and Gayatri or Swarna Sub1. Similarly, SR 26B, which coped with the stress by diluting the $\mathrm{Na}^{+}$load by maintaining a higher growth rate, differed from Pokkali or Nona Bokra: these two coped with the stress by regulating the transmission of $\mathrm{Na}^{+}$from roots to photosynthetically active sites. The $\mathrm{F}_{2: 3}$ population derived from Savitri $\times$ SR 26B showed wide morpho-physiological diversity for salt tolerance. SR 26B was the most distant genotype from Pokkali in the Saltol QTL region and was salt tolerant despite the absence of Pokkali alleles in this region.
\end{abstract}

Keywords: salt tolerance, principal component analysis, ion exclusion, Saltol QTL, genetic diversity

Abbreviations: SL: shoot length (cm), RL: root length (cm), DWS: dry weight of shoots per plant (mg), DWR: dry weight of roots per plant (mg), SNA: shoot $\mathrm{Na}^{+}$concentration $(\mu \mathrm{g} / \mathrm{mg})$, SNAC: shoot $\mathrm{Na}^{+}$content $(\mathrm{mg})$, SK: shoot $\mathrm{K}^{+}$concentration $(\mu \mathrm{g} / \mathrm{mg})$, SKC: shoot $\mathrm{K}^{+}$ content per plant $(\mathrm{mg}), \mathrm{SNA} / \mathrm{K}$ : shoot $\mathrm{Na}^{+} / \mathrm{K}^{+}$ratio, RNA: root $\mathrm{Na}^{+}$concentration $(\mu \mathrm{g} / \mathrm{mg})$, RNAC: root $\mathrm{Na}^{+}$content per plant $(\mathrm{mg}), \mathrm{RK}$ : root $\mathrm{K}^{+}$concentration $(\mu \mathrm{g} / \mathrm{mg}), \mathrm{RKC}$ : root $\mathrm{K}^{+}$ content per plant (mg), RNA/K: root $\mathrm{Na}^{+} / \mathrm{K}^{+}$ratio, TNAC: total $\mathrm{Na}^{+}$content per plant $(\mathrm{mg})$, TKC: total $\mathrm{K}^{+}$content per plant $(\mathrm{mg}), \mathrm{PNA} / \mathrm{K}$ : plant $\mathrm{Na}^{+} / \mathrm{K}^{+}$ratio, $\mathrm{GTH}$ : growth rate $(\%), \mathrm{SES}$ : standard evaluation system score (on a scale from 1 to 9 ), $\mathrm{CV}$ : coefficient of variance, $\mathrm{CD}$ : critical difference, SEM: standard error of mean, MSS: mean sum of squares, SD: standard deviation, QTL: quantitative trait loci

* Corresponding author; E-mail: krishnenducrri@gmail.com 


\section{Introduction}

Rice is the staple food of South Asia and South East Asia, grown in diverse agro-ecological regions including coastal areas. Among many abiotic sources of stress, salinity is the most serious, and a major cause of low productivity of rice in coastal plains. Following the rise in sea level due to higher temperatures, local landraces have replaced high-yielding rice varieties in many areas along India's eastern coast. In some cases, lands are no longer suitable for rice cultivation. Although several salt-tolerant landraces of cultivated rice and wild rice (e.g. Oryza croactata) had been identified as donors, the lines bred from such donors have not proved as tolerant. Many quantitative trait loci (QTLs) for this polygenic trait have since been identified in rice, of which Saltol is the most widely recognized and major QTL for salt tolerance at the seedling stage. Saltol was identified from a population derived from IR $29 \times$ Pokkali (Singh et al. 2007). However, the level of tolerance in lines derived from marker-assisted selection for Saltol QTL has not always been comparable to that shown by Pokkali and FL478, a Saltol-introgression line (Thomson et al. 2010), probably because of additional QTLs in Pokkali with epistatic effects for many unexplained tolerance mechanisms. Apart from Pokkali, many other landraces and pure lines with varying degrees of salt tolerance have been identified, but the pattern and nature of tolerance in these genotypes have rarely been studied (Singh and Flower 2010). Among the tested lines, genetic variation was observed even within the salt-exclusion mechanism found to be predominant in rice (Platten et al. 2013). It is therefore important to identify new sources of tolerance with different tolerance mechanisms and introgress them in high-yielding backgrounds for obtaining higher levels of salt tolerance. Among the introgression lines, the degree of tolerance varies with the genetic background (Thomson et al. 2010), which underscores the importance of identifying suitable parental combinations for achieving the desired tolerance level and a high yield potential - and two diverse genotypes, through hybridization, can produce many transgressive segregants with these two attributes (Rauf et al. 2010). However, a suitable background with the desired plant type is also required for combating other major sources of stress such as waterlogging, which often occur in the wet season along the coastal saline belt of eastern India.

The present study sought to assess plant growth and ion accumulation in response to salt stress at the seedling stage and to examine the maker-allelic variability in the Saltol QTL region. The knowledge thus gained will be useful in widening the understanding of the molecular and phenotypic diversity among the parental lines currently used in developing, through hybridization, elite salt-tolerant lines for coastal areas.

\section{Materials and Methods}

\section{Plant materials}

The plant material comprised both salt-susceptible and salt-tolerant varieties and lines. The salt-susceptible parents were Savitri, Gayatri, and Swarna Sub1, which are popular rice varieties in rain-fed shallow lowlands (water depth 0-30 cm), and Varshadhan, which 
is popular in semi-deep, waterlogged lowlands (water depth $0-50 \mathrm{~cm}$ ). The salt-tolerant parents were FL 496, Pokkali (AC 41585), Nona Bokra, Rahspunjar, and SR 26B. IR 29 was included as the susceptible check for salt tolerance at the seedling stage (Table 1). These genotypes have been used in breeding salt-tolerant rice cultivars for rain-fed coastal saline areas. SR 26B is the most popular variety in the coastal saline areas of eastern India, which makes it particularly important to develop it further for high yield potential. Accordingly, $150 \mathrm{~F}_{2: 3}$ lines derived from Savitri $\times$ SR $26 \mathrm{~B}$ were also taken up subsequently in the present study.

\section{Location, plant culture, and salinity treatments}

The experiments were conducted in a net house at the Central Rice Research Institute, Cuttack, India $\left(20.5^{\circ} \mathrm{N}, 85.83^{\circ} \mathrm{E}\right)$. Two separate experiments, laid out as a completely randomized design with three replications, were conducted, one in November-December 2009 and other in July-August 2010. The first comprised 10 parental lines and the second, $150 \mathrm{~F}_{2: 3}$ lines and replicated checks (IR29 as the susceptible type and FL478 as the tolerant type). In November-December 2009, the average maximum and minimum temperatures, relative humidity, and sunshine hours were $27.4{ }^{\circ} \mathrm{C}, 19.2{ }^{\circ} \mathrm{C}, 52 \%-92 \%$, and $6.7 \mathrm{~h}$; in July-August 2010, the corresponding values were $30.8^{\circ} \mathrm{C}, 25.5^{\circ} \mathrm{C}, 78 \%-92 \%$, and $3.3 \mathrm{~h}$. Seeds were incubated at $55^{\circ} \mathrm{C}$ for 5 consecutive days to break dormancy if any and to ensure uniform germination. The pre-germinated seeds of each genotype were placed on styrofoam seedling floats supported on plastic trays filled with Yoshida nutrient solution (Yoshida et al. 1976). Each float had 10 compartments. The seedlings were allowed to grow for 3 days and enough $\mathrm{NaCl}$ was added to the nutrient solution to attain an $\mathrm{EC}$ of $6 \mathrm{dS}$ $\mathrm{m}^{-1}$. After 3 more days of growth at that level of salinity, it was raised to $12 \mathrm{dS} \mathrm{m}^{-1}$ by adding $6 \mathrm{~g} \mathrm{NaCl}$ per litre of the nutrient solution.

\section{Samplings and measurements}

When the susceptible check IR 29 showed severe symptoms of salt stress, all the genotypes were scored visually for tolerance on a scale of 1 to 9 using the modified standard evaluation system (SES) of IRRI (Gregorio et al. 1997). Shoot length $(\mathrm{cm})$ and root length $(\mathrm{cm})$ of 10 seedlings in each replication were recorded and the growth rate was calculated as the percent increment of shoot length during the period from the time the higher level of stress was introduced $\left(12 \mathrm{dS} \mathrm{m}^{-1}\right)$ to the end of the first experiment, that is when the susceptible check showed severe symptoms. In the second experiment, dry weights of shoots and roots and concentrations of $\mathrm{Na}$ and $\mathrm{K}$ were recorded for 5 seedlings of each of the 150 $\mathrm{F}_{2: 3}$ lines and the checks (IR29 and FL478). The plant samples were oven-dried at $70{ }^{\circ} \mathrm{C}$ for 5 days before recording their weights. For determining the $\mathrm{Na}$ and $\mathrm{K}$ concentrations, the procedure described by Yoshida et al. (1976) was followed: the samples were pooled, finely ground, and analysed by flame photometry after $48 \mathrm{~h}$ of extraction of $15 \mathrm{mg}$ lots of samples with $30 \mathrm{ml}$ of $1 \mathrm{~N} \mathrm{HCl}$. 


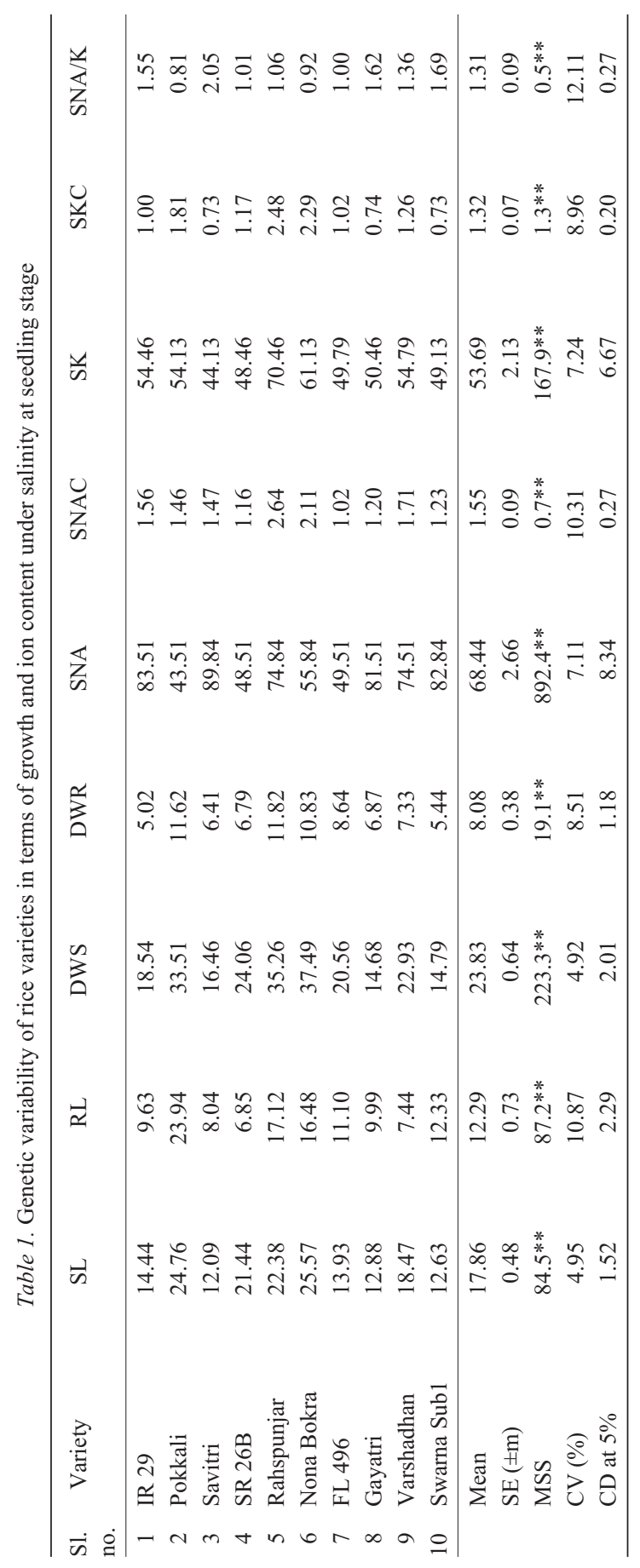

Cereal Research Communications 43, 2015 


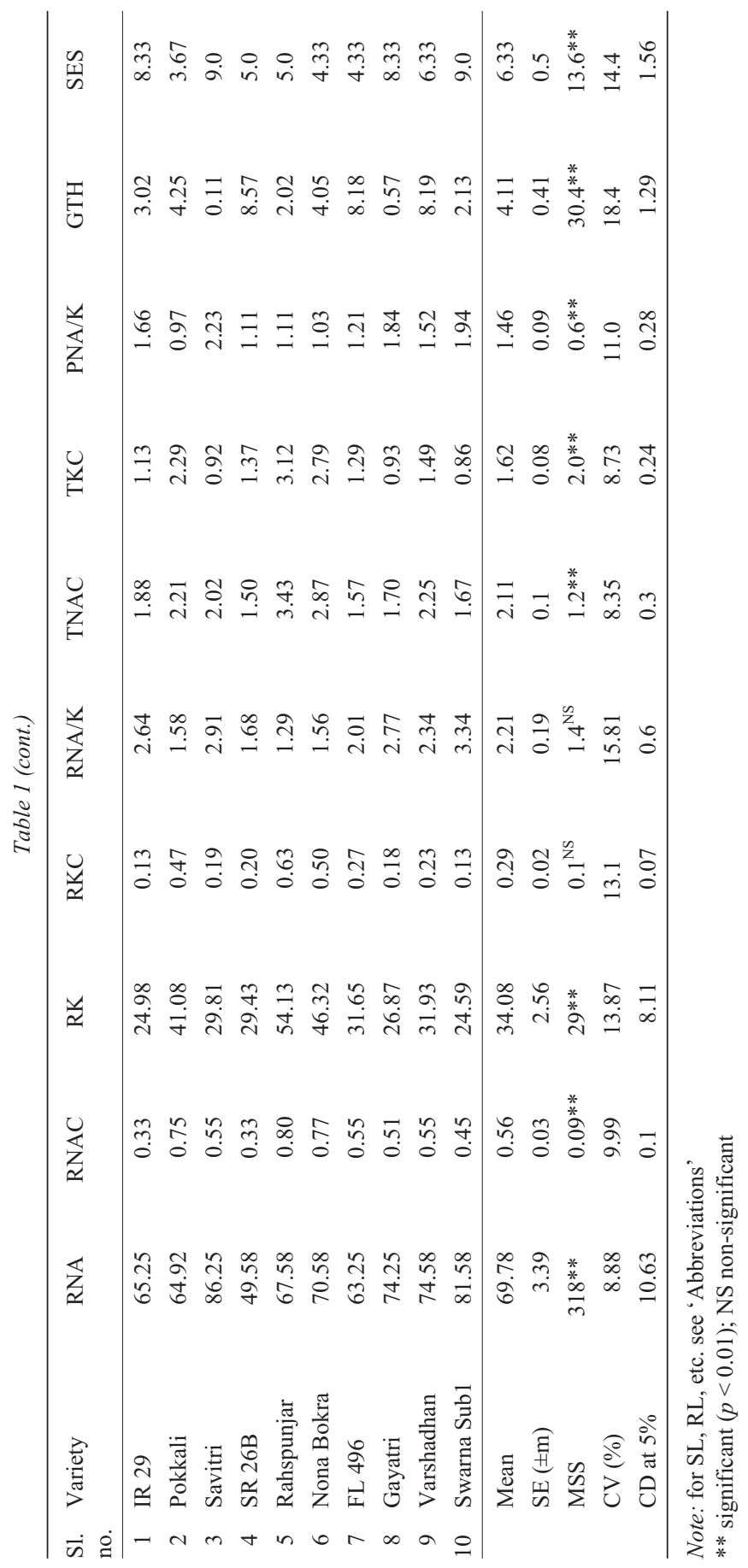

Cereal Research Communications 43, 2015 


\section{DNA isolation and amplification}

Fresh leaves from 5 plants of each genotype were pooled, cut into small pieces, and samples, each weighing $0.5-1.0 \mathrm{~g}$, were set aside. The samples were crushed under liquid nitrogen and the DNA was isolated using the standard procedure (Rogers and Bendich 1988). Eleven SSR primers from the IRGSP custom-designed insertion/deletion (indel) markers and gene-based PCR markers, including SKC1, SalT, and a pectinesterase gene (Thomson et al. 2010) from a 11.0-12.2 Mb region of the Saltol QTL region were tested for polymorphism (Table $\mathrm{S} 1 *$ ). Polymerase chain reactions were performed in a volume of $25 \mu$ l containing $10 \mathrm{mM}$ Tris-HCl buffer (pH 8.2), $50 \mathrm{mM} \mathrm{KCl}, 1.5 \mathrm{mM} \mathrm{MgCl}_{2}, 0.01 \%$

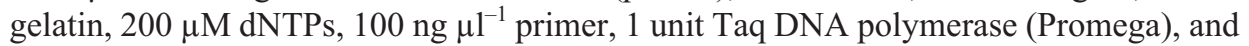
$100 \mathrm{ng}$ template DNA. The amplification reaction consisted of preheating for $5 \mathrm{~min}$ at 94 ${ }^{\circ} \mathrm{C}, 35$ cycles of $1 \mathrm{~min}$ at $94{ }^{\circ} \mathrm{C}$ (denaturation), $1 \mathrm{~min}$ at $55-61^{\circ} \mathrm{C}$ (annealing), and $3 \mathrm{~min}$ at $72{ }^{\circ} \mathrm{C}$ (elongation), followed by $7 \mathrm{~min}$ (extension) at $72^{\circ} \mathrm{C}$ in a PCR system (Bio-Rad). Amplified products were separated in $6 \%$ polyacrylamide gel. The separated PCR products were made visible under ultraviolet light and photographed using a Kodak Electrophoresis Documentation and Analysis System.

\section{Data analysis}

Analysis of variance (ANOVA) was carried out for all the morpho-physiological parameters taken for the study. Relationships of the tolerance score (SES) with the other parameters were computed using Pearson's correlation coefficient $(r)$. All the analysis was carried out using SPSS ver. 15.0.

For the microsatellite DNA fingerprinting of rice genotypes, polymorphism was scored for the presence or absence of bands on polyacrylamide gel on a 1/0 basis. Polymorphic information content (PIC) was calculated as described by Anderson et al. (1993) based on the allelic patterns of all the genotypes. Cluster analysis of the marker data was carried out using Jaccard's similarity coefficients with the unweighted pair group method with arithmetic mean (UPGMA). Principal component analysis (Jolliffe 1986) was carried out using eigen vectors and genotypes were projected on a three-dimensional scatter plot based on the major principal components derived from both phenotypic and genotypic data. All the analyses were carried out using NTSYS-PC ver. 2.11f (Rohlf 2000). The F test $(p<0.01)$ was used for finding out the association of markers with phenotypes.

\section{Results}

\section{Estimation of morpho-physiological traits and diversity of parental lines}

Analysis of variances revealed significant genotypic differences, except for root $\mathrm{K}^{+}$content and root $\mathrm{Na}^{+}-\mathrm{K}^{+}$ratio (Table 1 ). Susceptibility to salinity was significantly and negatively correlated with shoot length $(r=-0.76)$, root length $(r=-0.53)$, shoot dry weight $(r=-0.77)$, root dry weight $(r=-0.73)$, percent increment of shoot length (growth rate)

\footnotetext{
* Further details about the Electronic Supplementary Material (ESM) can be found at the end of the article.
} 
$(r=-0.55)$, shoot $\mathrm{K}^{+}$concentration $(r=-0.42)$ and $\mathrm{K}^{+}$content $(r=-0.69)$, root $\mathrm{Na}^{+}$content $(r=-0.49)$ and root $\mathrm{K}^{+}$concentration $(r=-0.60)$, root $\mathrm{K}^{+}$content $(r=-0.68)$, and total plant $\mathrm{K}^{+}$content $(r=-0.70)$. Susceptibility was also positively and significantly correlated with shoot $\mathrm{Na}^{+}$concentration $(r=0.84)$, root $\mathrm{Na}^{+}$concentration $(r=0.56)$, shoot $\mathrm{Na}^{+}-\mathrm{K}^{+}$ ratio $(r=0.87)$, root $\mathrm{Na}^{+}-\mathrm{K}^{+}$ratio $(r=0.81)$, and total plant $\mathrm{Na}^{+}-\mathrm{K}^{+}$ratio $(r=0.87)$ (Table $\mathrm{S} 2)$. Therefore, the genotypes that grew faster and had lower $\mathrm{Na}^{+}-\mathrm{K}^{+}$ratio in shoots, roots, and the whole plant under salt stress were tolerant. Pokkali and Nona Bokra were taller and had longer roots and greater shoot and root biomass than the rest of the genotypes. Rahspunjar also had greater biomass than the others (Table 1). These three genotypes proved more tolerant to salt stress. SR 26B, FL 496, and Varshadhan also grew approximately $8 \%$ faster than other genotypes under salinity stress. $\mathrm{Na}^{+}$concentration in shoots was higher in Savitri, Gayatri, and IR 29 than that in Pokkali, SR 26B, and FL 496 (Table 1). In the tolerant varieties, shoot $\mathrm{Na}^{+}$concentrations were lower and shoot $\mathrm{K}^{+}$concentrations were higher. Faster growth and greater biomass helped SR 26B to dilute the accumulated ions. Rahspunjar recorded the highest values of $\mathrm{K}^{+}$concentration and $\mathrm{K}^{+}$ content, followed by Nona Bokra.

Susceptibility to salt stress (SES $=7-9$ ) was associated with higher values of plant $\mathrm{Na}^{+}-\mathrm{K}^{+}$ratio (Savitri, 2.23; Swarna Sub1, 1.94; Gayatri, 1.84; IR 29, 1.66) and tolerance or moderate tolerance (SES $=3-5$ ) with lower values (Pokkali, 0.97; Nona Bokra, 1.03; SR 26B, 1.11; Rahspunjar, 1.11; FL 496, 1.21). The moderate level of susceptibility (SES $=6-7$ ) of Varshadhan was also associated with intermediate values of $\mathrm{Na}^{+}-\mathrm{K}^{+}$ratio (1.52) (Fig. S1*). The susceptible cultivars accumulated larger amounts of $\mathrm{Na}^{+}$and smaller amounts of $\mathrm{K}^{+}$in roots and shoots than the tolerant cultivars did. Between the two types of tissue, roots accumulated larger amounts of $\mathrm{Na}^{+}$and smaller amounts of $\mathrm{K}^{+}$than shoots did. Significant negative correlations were found between $\mathrm{Na}^{+}$content and the growth of roots and shoots.

The farthest genetic distance was between Swarna Sub 1 and Rahspunjar, followed by that between Savitri and Rahspunjar (Table S3). Principal component analysis jointly explained $94.5 \%$ of the variability: PC 1 alone explained $67.8 \%$ of the variability and comprised the positive effect of shoot length, biomass, shoot $\mathrm{K}^{+}$concentration and content, root $\mathrm{Na}^{+}$content, and root $\mathrm{K}^{+}$concentration and total $\mathrm{K}^{+}$content of the plant. PC 2 (positive effect of the rate of plant growth) explained $20.8 \%$ of the variability. Savitri, Gayatri, and Swarna Sub1 - all susceptible to salinity - occupied a special location on the 3-D plot whereas the tolerant and moderately tolerant lines occupied separate places, distant from one another: Rahspunjar and SR 26B occupied two far corners, and SR 26B was far away from Pokkali (Fig. 1a).

\section{Assaying parental lines with Saltol markers}

Parental lines were assayed by using polymorphic Saltol primers such as RM10694, AP 3206, SKC 1, RM 3412, RM10745, and Peck 4. Eighty-seven polymorphic bands were distributed in 21 marker-alleles. The highest number of alleles (7) was delivered by RM 3412 (Fig. S2). Banding positions in polyacrylamide gel varied from $165 \mathrm{bp}$ (SKC 1) to 240 bp (RM 10694) (Table S1). The least similarity in the Saltol region was observed be- 
tween Pokkali and SR 26B and the most between Varshadhan and IR 29 (Table S4). Principal component analysis based on markers in the Saltol QTL region of chromosome 1 led to the following positions on the 3-D plot: the moderately tolerant genotypes Rahspunjar and Nona Bokra were close to each other but distant from other genotypes including Pokkali, and SR 26B and Pokkali were also distant from each other (Fig. 1b). The posi-

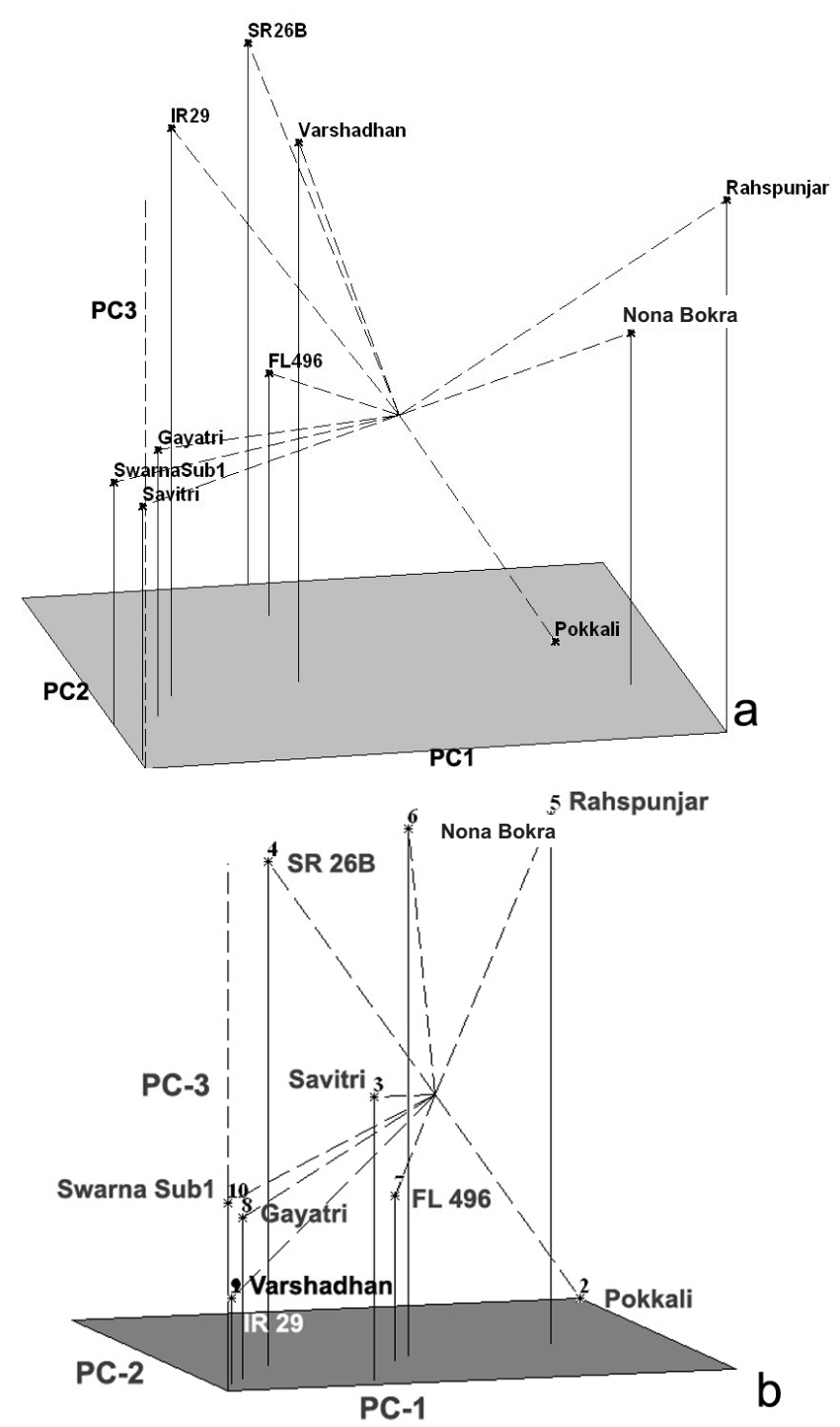

Figure 1. 3-D plot derived from principal component analysis based on a) morpho-physiological traits and b) SSR-polymorphism in the Saltol QTL region of ten rice genotypes 
tional symmetry of the salt-tolerant lines SR 26B, Pokkali, Rahspunjar, and Nona Bokra in both the 3-D plots shows that diversity in the Saltol QTL region varies more or less linearly with the phenotypic expression of salt tolerance.

SR 26B differed substantially from Pokkali in terms of molecular as well as morphophysiological traits related to salt tolerance at the seedling stage and was investigated further by studying the $\mathrm{F}_{2: 3}$ population derived from Savitri $\times$ SR 26B, a combination representing parents widely divergent in terms of phenotype and polymorphism in the Saltol QTL region. It was noteworthy that when the humidity was high, symptoms of salt stress in the susceptible check, namely IR 29, appeared sooner in this part of the experiment than they did in the earlier part. Phenotyping of the $\mathrm{F}_{2: 3}$ population showed that shoot length, shoot dry weight, and $\mathrm{Na}^{+}$and $\mathrm{K}^{+}$concentrations and their ratio were significantly different under salt stress at the seedling stage (Table S5) and the frequency distribution of salt tolerance (as rated under the SES) was continuous. In general, salt-tolerant lines with a low SES score (3-5) showed lower concentrations of $\mathrm{Na}^{+}$and higher concentrations of $\mathrm{K}^{+}$ (Fig. S3) and therefore a lower $\mathrm{Na}^{+}-\mathrm{K}^{+}$ratio (Table S6). Among the Saltol markers tested, RM3412 and RM10745 were polymorphic for both the parents. Single-marker analysis using one-way ANOVA was employed to find out whether these markers co-segregate with the tolerant phenotype associated with Saltol QTL. However, the F test $(p<0.01)$ indicated that none of these component traits related to salt tolerance was associated with the markers in the Saltol region.

\section{Discussion}

Pokkali is a well-known salinity tolerant donor in rice breeding programmes. The physiology of salt tolerance in this cultivar has been studied extensively, and a Saltol QTL underlying the salt-exclusion mechanism located in the 11.2-12.2 Mb region of the short arm of chromosome 1 was identified and successfully employed in marker-assisted selection (Islam et al. 2012; Gregorio et al. 2013). Apart from Pokkali, many salt-tolerant lines have been identified and documented by researchers all over the world (Chattopadhyay et al. 2014). Many morpho-physiological traits have been found useful for identifying salt-tolerant lines. Among them, initial plant vigour and lower amounts of accumulated toxic ions were recognized as particularly important determinants in assessing tolerance to salinity at the early vegetative stage in rice (Munns and Tester 2008). The present investigation has revealed wide variability among parental lines in terms of these two traits when subjected to salt stress. In an earlier analysis of physiological traits contributing to salt tolerance in rice, vigour was found to explain a greater proportion of the variance than $\mathrm{Na}^{+}$concentration or tissue tolerance (Yeo et al. 1990). In the present experiment, initial seedling vigour and higher biomass helped the tolerant lines to reduce the effect of stress exerted primarily by osmotic pressure and secondarily by the accumulation of toxic ions. However, growth rate of those varieties was substantially affected by the later phase of the salinity stress (12 $\mathrm{dS} \mathrm{m}^{-1}$ ). Since neither the degree nor the duration of stress was extended in the present study beyond this level, it is not possible to prove a definite link between the rate of growth and tolerance to salt. In the initial phase of the stress, Varshadhan was able to maintain its 
higher growth rate but, in the absence of any tolerance mechanism, failed to withstand the accumulation of toxic ions later; on the other hand, the tolerance mechanism in SR 26B enabled it to cope with such accumulation. The higher seedling vigour of salt-tolerant lines such as Pokkali and SR 26B, which helped them in producing greater biomass and, by dilution, further widened the difference in $\mathrm{Na}^{+}$concentrations between the salt-tolerant and salt-susceptible types.

In salt-sensitive crop plants such as rice, osmotic effects are typically expressed in two possible ways: either as the toxic effects of $\mathrm{Na}^{+}$on metabolic processes or as reduction in the uptake of $\mathrm{K}^{+}$ions (Yeo 2007). Given their similarities in ionic radius and ion-hydration energy, $\mathrm{Na}^{+}$competes with $\mathrm{K}^{+}$for crucial binding sites in major metabolic processes in the cytoplasm (Shabala and Cuin 2008). In addition, examining the salt content of shoots is appropriate because most of the $\mathrm{Na}^{+}$that is delivered to the shoots remains there (Munns and Tester 2008). In the present investigation also, $\mathrm{Na}^{+}$concentration and total $\mathrm{Na}^{+}$content in the shoot were positively correlated with susceptibility. The more tolerant cultivars had the ability to avoid the accumulation of $\mathrm{Na}^{+}$in large quantities and to absorb enough $\mathrm{K}^{+}$to maintain a low $\mathrm{Na}^{+}-\mathrm{K}^{+}$ratio required for normal metabolism. High external concentrations of $\mathrm{Na}^{+}$interfered with the normal uptake of $\mathrm{K}^{+}$, leading to lower $\mathrm{K}^{+}$concentrations as well as lower $\mathrm{K}^{+}-\mathrm{Na}^{+}$ratios (Zhang et al. 2010). A low $\mathrm{Na}^{+}-\mathrm{K}^{+}$ratio is often considered a desirable trait because it maintains the ions in balance and thus contributes to salt tolerance (Lee et al. 2003; Munns and Tester 2008). Na-exclusion through the root system, although well documented in Pokkali, might not be the only means of avoiding the toxic effect of $\mathrm{Na}^{+}$by means of a lower $\mathrm{Na}^{+}-\mathrm{K}^{+}$ratio: genetic variation in the salt-exclusion mechanism also led to lower $\mathrm{Na}^{+}$concentrations in the leaf blade (Platten et al. 2013). Principal component analysis in the present study showed that tolerant genotypes were widely dispersed on a 3-D plot, implying that no single genotype contains all the morpho-physiological traits related to salinity tolerance. Negrao et al. (2013) used EcoTiLLING with key genes known to be related to salt tolerance and found that different rice genotypes had different mechanisms to combat the detrimental effects of salt stress and that no single accession carried all the favourable alleles of the target loci. Thus, salt tolerance in rice can be increased beyond the present level by using multiple donors widely different in their morpho-physiological traits that confer tolerance to salinity. Although Rahspunjar accumulated larger quantities of $\mathrm{Na}^{+}$in its shoots than other tolerant genotypes did, higher $\mathrm{K}^{+}$ accumulation in its shoots helped this landrace in combating the toxic effects of $\mathrm{Na}^{+}$and maintaining ion homeostasis: Rahspunjar might not have been successful in preventing $\mathrm{Na}^{+}$exclusion in the first place but was able to cope with the problem by taking in greater quantities of $\mathrm{K}^{+}$and thereby maintaining a higher $\mathrm{K}^{+}-\mathrm{Na}^{+}$ratio. It has also been reported that, in rice, $\mathrm{Na}^{+}$and $\mathrm{K}^{+}$are mediated by different transporters (Garciadebleas et al. 2003). The genes determining the uptake of the two ions appear to be part of different linkage groups (Koyama et al. 2001; Lin et al. 2004). Garcia et al. (1997) suggest that in selecting parental crossing material for salt tolerance, $\mathrm{Na}^{+}$and $\mathrm{K}^{+}$content should be considered separately. Rahspunjar should have turned out to be susceptible, considering its inability to prevent the accumulation of toxic $\mathrm{Na}^{+}$ions in shoots; yet, it proved tolerant and was found to deploy a different mechanism, namely promoting higher accumulation of $\mathrm{K}^{+}$ions and 
suppressing their depletion in leaf tissues, resulting in reduction of $\mathrm{Na}^{+}$uptake despite higher concentrations of external $\mathrm{NaCl}$. A high-affinity $\mathrm{K}^{+}$transporter (HAK/KUP) prevented $\mathrm{Na}^{+}$influx at high $\mathrm{Na}^{+}$concentrations (Negrao et al. 2013). The up-regulation of OsCHX11 also facilitated significantly higher $\mathrm{K}^{+}$concentrations (Senadheera et al. 2009). Apart from $H K T 1 ; 4$ and $H K T 1 ; 5$, reported to be primarily accountable for $\mathrm{Na}^{+}$exclusion, the presence of the latter in some tolerant lines was found to balance the effect of $\mathrm{Na}^{+}$and lower the ratio of $\mathrm{Na}^{+}-\mathrm{K}^{+}$. In the present study, Rahspunjar was found to have a unique mechanism to balance the excess uptake and accumulation of $\mathrm{Na}^{+}$in shoots, leading to a lower $\mathrm{Na}^{+}-\mathrm{K}^{+}$ratio required for normal plant metabolism. This genotype could therefore be a useful donor in breeding rice for tolerance to salinity.

Plant tissues prevent excessive accumulation of toxic ions in their cytoplasm in three ways: exclusion, excretion, and dilution (Ben-Rais et al. 1993). The higher concentration of $\mathrm{Na}^{+}$in roots observed in the present experiment is consistent with the results of an earlier study (Akita and Cabuslay 1990). The higher $\mathrm{Na}^{+}$concentration in roots indicates exclusion of $\mathrm{Na}^{+}$in Pokkali and FL 496. Saltol QTL was associated with this exclusion mechanism, in which tolerant plants cannot only prevent normal translocation of toxic ions through the xylem to photosynthetically active tissues but also facilitate recirculation of $\mathrm{Na}^{+}$from shoots to roots (Berthomieu et al. 2003). Therefore, high $\mathrm{Na}^{+}$concentration in roots is frequently seen in those genotypes that possess the Saltol QTL. In the present experiment, $\mathrm{Na}^{+}$concentration in roots was found to be lower in SR 26B than in Pokkali or FL 496. Translocation of $\mathrm{Na}^{+}$from the younger to the older tissue is one possible mechanism to reduce the concentration of toxic ions in metabolically active tissues. This was evident from the large number of dried leaves (data not supplied) without any significant effect on plant growth since the plant continued to produce fresh leaves. SR 26B is derived from a salt-tolerant landrace, Kalambank, a popular cultivar in coastal saline areas of eastern India. Our data show the difference between SR 26B and Pokkali in terms of morpho-physiological traits related to salt tolerance at the seedling stage. Earlier work has shown significant diversity in the Saltol QTL region (Thomson et al. 2010), which could be harnessed in identifying new sources of tolerance. The wide separation of SR 26B and Rahspunjar from Pokkali in the Saltol QTL region seen in the 3-D plot suggests that each is unique and distinct. Our data show the greatest allelic difference between SR 26B and Pokkali in the Saltol QTL region, and the difference is further supported by the non-significant association between Saltol markers RM 10745 or RM 3412 with the tolerant phenotype. In other words, the tolerant reaction of SR 26B might not be due solely to the Saltol QTL, and SR 26B could be a new source of QTL that complements the effect of Saltol QTL. Populations derived from SR 26B and Rahspunjar could be analysed further for identifying new QTLs that complement the effect of Saltol to enhance salt tolerance through pyramiding the breeding lines. Diverse parental combinations were detected on the basis of the wide genetic distance between high-yielding plant lines and salt-tolerant lines. Parental combination such as Swarna Sub1 $\times$ Rahspunjar and Savitri $\times$ SR $26 \mathrm{~B}$ can produce many transgression segregants with higher salt tolerance as well as a high yield potential. 


\section{Acknowledgements}

The authors would like to thank the anonymous reviewers for their comments on the paper. This work was supported by the Central Rice Research Institute, Cuttack and the National Initiative on Climate Resilient Agriculture (NICRA, ICAR).

\section{References}

Akita, S., Cabuslay, G.S. 1990. Physiological basis of differential response to salinity in rice cultivars. Plant Soil 123:227-294.

Anderson, J.A., Churchill, G.A., Autrique, J.E., Tanksley, S.D., Sorrells, M.E. 1993. Optimizing parental selection for genetic linkage maps. Genome 36:181-186.

Ben-Rais, L., Alpha, M.J., Bhal, J. 1993. Lipid and protein contents of jojoba leaves in relation to salt adaptation. Plant Physiol. 31:547-557.

Berthomieu, P., Conejero, G., Nublat, A., Brackenbury, W.J., Lambert, C., Savio, C., Uozumi, N., Oiki, S., Yamada, K., Cellier, F., Gosti, F., Simonnean, T., Essah, P.A., Tester, M., Very, A. A., Sentenac, H., Casoe, F. 2003. Functional analysis of AtHKT1 in Arabidopsis shows that $\mathrm{Na}(+)$ recirculation by the phloem is crucial for salt tolerance. EMBO J. 22:2004-2014.

Chattopadhyay, K., Nath, D., Mohanta, R.L., Bhattacharyya, S., Marndi, B.C., Nayak, A.K., Singh, D.P., Sarkar, R.K., Singh, O.N. 2014. Diversity and validation of microsatellite markers in Saltol-QTL region in contrasting rice genotypes for salt tolerance at the early vegetative stage. Aus. J. Crop Sci. 8:356-362.

Garcia, A., Rizzo, C.A., Uddin, J., Bartos, S.L., Senadhira, D., Flowers, T.J., Yeo, A.R. 1997. Sodium and potassium transport to the xylem are inherited independently in rice, and the mechanism of sodium: Potassium selectivity differs between rice and wheat. Plant Cell Environ. 20:1167-1174.

Garciadebleas, B., Senn, M.E., Bañuelos, M.A., Rodriquez-Navarro, A. 2003. Sodium transport and HKT transporters: the rice model. Plant J. 34:788-801.

Gregorio, G.B., Islam, M.R., Vergara, G.V., Thirumeni, S. 2013. Recent advances in rice science to design salinity and other abiotic stress tolerant rice varieties. SABRAO J. Breed. Genet. 45:31-41.

Gregorio, G.B., Senadhira, D., Mendoza, R.I. 1997. Screening rice for salinity tolerance. IRRI Discussion paper series no. 22. BRRI, Philippines, pp. 1-30.

Islam, M.R., Gregorio, G.B., Salam, M.A., Collard, B.C.Y., Singh, R.K., Hassan, L. 2012. Validation of SalTol linked markers and haplotype diversity on chromosome 1 of rice. Mol. Plant Breed. 3:103-114.

Jolliffe, I.T. 1986. Principal Component Analysis. Springer-Verlag, Berlin.

Koyama, L.M., Levesley, A., Koebner, R.M.D., Flowers, T.J., Yeo, A.R. 2001. Quantitative trait loci for component physiological traits determining salt tolerance in rice. Plant Physiol. 125:406-422.

Lee, K.S., Choi, W.Y., Ko, J.C., Kim, T.S., Gregorio, G.B. 2003. Salinity tolerance of japonica and indica rice (Oryza sativa L.) at the seedling stage. Planta 216:1043-1046.

Lin, H.X., Zhu, M.Z., Yano, M., Gao, J.P., Liang, Z.W., Su, W.A., Hu, X.H., Ren, Z.H., Chao, D.Y. 2004. QTLs for $\mathrm{Na}+$ and $\mathrm{K}+$ uptake of the shoots and roots controlling rice salt tolerance. Theor. Appl. Genet. 108:253-260

Munns, R., Tester, M. 2008. Mechanisms of salinity tolerance. Ann. Rev. Plant Bio. 59:651-681.

Negrao, S., Almadanim, M.C., Pires, I.S., Abreu, I.A., Maroco, J., Courtois, B., Gregorio, G.B., McKnally, K.L., Oliviera, M.M. 2013. New allelic variants found in key rice salt-tolerant genes: an association study. Plant Biotech. J. 11: 87-100.

Platten, J.D., Egdane, J.A., Ismail, A.M. 2013. Salinity tolerance, Na+ exclusion and allele mining of HKT 1;5 in Oryza sativa and O. glaberrima: many sources, many genes, one mechanism? BMC Plant Biol. 13:32.

Rauf, S., Teixeira de Silva, J.A., Khan, A.A., Naveed, A. 2010. Consequences of plant breeding on genetic diversity. Internal. J. Plant Breed. 4:1-21.

Rogers, S.O., Bendich, A.J. 1988. Extraction of DNA from plant tissues. In: Gelvin S.B., Schilperoort, R.A. (eds), Plant Molecular Biology Manual. Kluwer Academic Publishers, Boston, MA, USA, pp. A6:1-10

Rohlf, F.J. 2000. NTSYS-pc Numerical Taxonomy and Multivariate Analysis System version 2.1. Applied Biostatistics, New York, USA. 
Senadheera, P., Singh, R.K., Maathuis, F.J.M. 2009. Differentially expressed membrane transporters in rice roots may contribute to cultivar dependent salt tolerance. J. Exp. Bot. 60:2553-2563.

Shabala, S., Cuin, T.A. 2008. Potassium transport and plant salt tolerance. Physio. Plant 133:651-669.

Singh, R.K., Gregorio, G.B., Jain, R.K. 2007. QTL mapping for salinity tolerance in rice. Physio. Mol. Bio. Plants 13:87-99.

Singh, R.K., Flowers, T.J. 2010. The physiology and molecular biology of the effects of salinity on rice. In Pessarakli, M. (ed.), Handbook of Plant and Crop Stress, $3^{\text {rd }}$ edn. Taylor and Francis, Florida, USA, pp. 901-942.

Thomson, M.J., De Ocampo, M., Egdane, J., Rahman, M.A., Sajise, A.G., Adorada, D.L., Tumimbang-Raiz, E., Blumward, E., Seraj, Z.I., Singh, R.K., Gregorio, G.B., Ismail, A.M. 2010. Characterizing the Saltol quantitative trait locus for salinity tolerance in rice. Rice 3:148-160.

Yeo, A. 2007. Salinity. In: Yeo, A.R., Flowers, T.J. (eds), Plant Solute Transport. Blackwell Publishing. London, UK. pp. 340-356.

Yeo, A.R., Yeo, M.E., Flowers, S.A., Flowers, T.J. 1990. Screening of rice (Oryza sativa L.) genotypes for physiological characters contributing to salinity resistance and their overall performance. Theor. App. Genet. 79:377-384.

Yoshida, S., Forno, D.A., Cock, J.H., Gomez, K.A. 1976. Laboratory Manual for Physiological Studies of Rice. $3^{\text {rd }}$ edn. IRRI. Los Banos, Philippines. pp. 61-66.

Zhang, J.L., Flowers, T.J., Wang, S.M. 2010. Mechanisms of sodium uptake by roots of higher plants. Plant Soil 326:45-60.

\section{Electronic Supplementary Material (ESM)}

Electronic Supplementary Material (ESM) associated with this article can be found at the website of CRC at http://www.akademiai.com/content/120427/

Electronic Supplementary Table S1. Primer tested for polymorphism of Saltol QTL region in parental lines

Electronic Supplementary Table S2. Correlation coefficient matrix of SES values with all the traits measured under salinity stress at seedling stage

Electronic Supplementary Table S3. Dist distance coefficients matrix derived from morpho-physiological traits of 10 rice genotypes

Electronic Supplementary Table S4. Jaccards similarity coefficients matrix derived from SSR polymorphism at the Saltol QTL region of 10 rice genotypes

Electronic Supplementary Table S5. Mean and variance of phenotypic parameters related to salt-tolerance in parent and $\mathrm{F}_{2: 3}$ population derived from Savitri $\times \mathrm{SR} 26 \mathrm{~B}$

Electronic Supplementary Table S6. $\mathrm{Na}^{+}$and $\mathrm{K}^{+}$concentration and ratio in parents (Savitri, SR 26B) and $150 \mathrm{~F}_{2: 3}$ lines derived from Savitri $\times \mathrm{SR} 26 \mathrm{~B}$ cross

Electronic Supplementary Figure S1. Graphical presentation in alteration of SES score in response to $\mathrm{Na}^{+}-\mathrm{K}^{+}$ ratio in shoot, root and total plant in 10 rice genotypes under salinity stress $\left(\mathrm{EC}=12 \mathrm{dSm}^{-1}\right)$

Electronic Supplementary Figure S2. Amplified DNA of 10 rice genotypes using microsatellite primer, RM3412 and gene-based primer, SKC1 linked with Saltol QTL after resolution in 6\% polyacrylamide gel.

(Lane 1: IR 29, 2: Pokkali, 3: Savitri, 4: SR 26B, 5: Rahspunjar, 6: Nona Bokra, 7: FL 496, 8: Gayatri, 9: Varshadhan, 10: Swarna Sub1, M: 100 bp ladder)

Electronic Supplementary Figure S3. Graphical representation of SES score and corresponding $\mathrm{Na}^{+}$ (blue line) and $\mathrm{K}^{+}$(red line) concentration in shoot of $150 \mathrm{~F}_{2: 3}$ lines derived from Savitri $\times$ SR $26 \mathrm{~B}$ cross 